\title{
A Signaling Explanation for Political Parties and Advertisements
}

\author{
Tamura Masaoki \\ Nagoya University of Commerce and Business, Nisshin, Japan \\ Email: tamuramasaoki@gmail.com
}

How to cite this paper: Masaoki, T. (2018) A Signaling Explanation for Political Parties and Advertisements. Theoretical Economics Letters, 8, 241-255.

https://doi.org/10.4236/tel.2018.83018

Received: December 7, 2017

Accepted: February 6, 2018

Published: February 9, 2018

Copyright $\odot 2018$ by author and Scientific Research Publishing Inc. This work is licensed under the Creative Commons Attribution International License (CC BY 4.0).

http://creativecommons.org/licenses/by/4.0/

\begin{abstract}
This study examines the signaling roles of political parties and political advertising. Although politicians' types are unobservable during an election, their party affiliations and political advertisements are observable to the voters. Through these two political behaviors, politicians can reveal their hidden types to the public. We extend Snyder and Ting [1] to a multi-period model with the possibility of reelection and examine the roles and relationships of political parties and advertisements. We show that political parties are not sufficient signals to reveal politicians' types. Political advertisements work as a complementary signal to political parties. With political parties and advertisements, voters can elect their favored candidates adequately. Even if the advertisements are a waste of money, they contribute to voting for favored candidates.
\end{abstract}

\section{Keywords}

Signaling, Political Economics, Reelection, Political Party, Political Advertisements

\section{Introduction}

For politicians in an election, joining political parties and creating political advertisements are important activities. First, many candidates belong to political parties, even if their own political standpoints seem different to some extent from the parties' political standpoints. Second, almost all political candidates make posters before elections. They sometimes spend enormous amounts of money on media advertising. Although voters observe these political advertisements, they often seem useless for the voters. Advertisements call out the candidates' names repeatedly, and do not inform the voters of any candidates' policy plannings. Then, these kinds of political parties and advertisements are often criticized as wastes of money. However, this study sheds light on the positive aspects of 
parties and advertisements; both joining political parties and advertising provide information about politicians' hidden types to voters. In other words, parties and advertisements function as signals to voters in the case of asymmetric information.

Because candidates' types are hidden and unknown to voters during an election, candidates send signals to differentiate themselves from other candidates. Snyder and Ting [1] show that if politicians' types are uncertain to voters, parties function as brand names (signals) that ensure the politicians' types to some extent in the same manner Spence's [2] signaling model. Since belonging to a party implies that a politician's policy is close to the party's ideal policy, it conveys information about that politician's hidden type.

Given this role of political parties, what is the role of political advertisements? If they also work as a signal, are they a substitute for or a complement of political parties? Related studies, like Alesina and Spear [3] and Harrington [4], do not answer these questions clearly. This study extends Snyder and Ting [1] to a multi-period model with the possibility of reelection and answers these questions. Political parties are not sufficient signals, and political advertisements serve as a complement to political parties.

Only a few studies [5] have analyzed reelection from theoretical point of view. One particular characteristic about reelections is that, after one term in office, the hidden type of the incumbent is completely revealed to the voters. In a second election, this fact can be an advantage for some of the incumbents, whose hidden types have been found to be favorable (i.e., ex-post good) to the voters. Such incumbents can be reelected. However, this fact can be a disadvantage for other incumbents whose hidden types have been found to be less favorable than expected (i.e., ex-post bad) to the voters in reality. Such incumbents cannot be reelected. In short, there are two types of politicians. The first type (ex-post good) can win the election twice, and the other type (ex-post bad) can win the election only once. The problem is that, in the first election, both types belong to parties, and voters cannot distinguish between the two types. In other words, voters may choose an ex-post bad politician in the first election. Thus, parties are not sufficient signals. Then, there is a possibility that political advertisements also work as an additional signal, even if they do not convey any information about the politicians' hidden types to the voters, and hence, they are simply a waste of money in the sense of Milgrom and Roberts [6] In the first election, candidates who can be reelected and win office twice (ex-post good) have stronger incentives than candidates who can win office only once. In addition to joining parties, ex-post good politicians create political advertisements and spend money to reveal their hidden type. Then, voters can choose only ex-post good candidates in the first election.

In Section 2, we overview Snyder and Ting [1] as the basic model. In Section 3, we introduce reelection to the basic model and, thereby, investigate the model in a dynamic environment. In other words, there is another election after a politi- 
cian has served one term in office. We find that political parties are not sufficient signals in the election. In Section 4, we introduce reelection and advertisements to the basic model. Political advertisements are complementary to political parties. Section 5 considers the difference between political parties and advertisements. Section 6 summarizes the main results.

\section{Basic Model: Snyder and Ting [1]}

What is the role of political parties? Why do politicians act not as one person but as a group? Snyder and Ting [1] give one answer to these questions. This section introduces the essence of Snyder and Ting [1]. There are three kinds of agents: voter, politician, and political party. The basic roles of them are as follows: the voters cast vote for candidate in the election. The politicians are candidates in the election, and hold the office if they get elected. The political parties are belonged to by the politicians. 1) The voters want to elect politicians whose political preferences are close to their own. However, politicians' preferences are unknown to the voters. This knowledge asymmetry is undesirable even for politicians whose hidden preferences are actually close to those of the voters. 2) There are two implications for a politician who joins a party. First, the fact that the politician has joined the party is revealed to the voters. Second, if he or she joins the party, then he or she has to obey the party's policy preferences. Thus, joining the party provides disutility to politicians whose preferences are far from those of the party. 3) Therefore, party membership informs voters that a politician's hidden preferences are actually close to the party's preferences.

\section{Introducing Reelection to the Basic Model}

\subsection{Timing of the Model}

First, by adding reelection to the basic model of Snyder and Ting [1], we would like to show that political parties are not sufficient signals. Snyder and Ting [1] consider a static model in which there is one election and one term in office. On the other hand, politicians can get reelected only in a dynamic model in which there are two elections. Adding the second election to the basic model, we analyze the consequences of reelections and the role of political parties.

The key feature of a reelection is that politicians completely reveal their types after one term in office. Although joining a party partially reveals a politician's type, conducting his ideal policy in his term of office is assumed to reveal his type. Because in Snyder and Ting [1] and in our model, politicians' types directly indicate their ideal policies, this assumption is natural.

There are three players in our model: candidates, political parties, and voters. Although there are two parties, there are numerous candidates and voters. The timing of our model is described as follows, but, in short, our model adds a second period (second election) to the model of Snyder and Ting [1].

1) First Period Starts. Party Platform Selection.

2) Candidate Nomination and Selection. 
3) 1st Vote. $1^{\text {st }}$ Term of Office.

4) Second Period Starts. Candidate Nomination and Selection.

5) 2 nd Vote. $2^{\text {nd }}$ Term of Office.

a) In the first period, political parties choose their platforms within the policy space $[-1,1]$, which is observed by all players. Each potential candidate and voter has a preferred policy that lies within $[-1,1]$ with a uniform distribution. Candidates' preferred policies are unobserved by the voters. Potential candidates choose to belong to parties or to be unaffiliated.

b) For each party, nature randomly selects one candidate who chooses to belong to that party for the election. This process means that parties cannot observe the candidates' hidden types.

c) During the first vote, although voters also cannot observe the candidates' hidden types, they can observe whether or not the candidates belong to the parties. The winner of the election is determined by the plurality rule. The winner of the election holds the office and gains a payoff. After one term in office, a politician's type is completely revealed to both parties and voters.

d) In the next period, the incumbent decides whether to run for reelection. The party also decides whether the incumbent will run for reelection or not. If the incumbent does not run for reelection, nature again selects a new candidate for that party. In addition, nature randomly selects one candidate who chooses to belong to the other party for the election.

e) In the second election, the winner is decided by plurality rule. The winner of the second election also holds the office and gains the same payoff as in the first election.

We should note that the decision to run for reelection is made by both the politician and the party to which he or she belongs. First, running for reelection must be profitable to the politician who now holds office. Second, the party must nominate a candidate for reelection who is more likely to win office than a newly nominated politician is. In other words, a politician runs for reelection only if the probability of his reelection is higher than that of a new candidate whose ideal policy is unknown to the public.

The remaining functional setup is as follows. The policy space is the range $[-1,1]$. The payoff of politician $i$ with an ideal point $z_{i}$ who is affiliated with party $k$ and wins office is

$$
w-c-\alpha\left(x_{k}-z_{i}\right)^{2},
$$

where $w$ denotes the rent of taking office, $c \in[0, w)$ denotes the cost of taking office, $x_{k}$ denotes the policy of political party $k$, and the coefficient $\alpha>0$. On the other hand, if a politician does not win, his or her payoff is 0 . Voters lie within $[-1,1]$ with a uniform distribution. The expected payoff of the median voter (who is located at zero in the policy space) if party $k^{2}$ s candidate $i$ wins is

$$
E\left[-\left(0-z_{i}\right)^{2}\right]=-\left(0-\mu_{i}\right)^{2}-\sigma_{i}^{2}
$$

where $\mu_{i}$ denotes the mean and $\sigma_{i}$ denotes the variance of the candidate of 
party $i$.

\subsection{The Equilibrium}

We deal with the case in which there are two political parties and both of them choose the platform $x_{i}=0^{1}$. This case is natural because the median voter is also at 0 . In other words, both parties target the median voter, and they suggest the same policy.

First, we consider the behavior of politicians in each period. We use backward induction. In the second period, the incumbent who won the first period election has to compete against a candidate from the other party. We call this new candidate of the opponent party the "challenger". Then, the expected payoff of the median voter at 0 if the challenger is elected is

$$
-(0-0)^{2}-\frac{\theta^{2}}{3},
$$

where $\theta \equiv \sqrt{\frac{w-c}{\alpha}}$. Note that a candidate joins a political party if his or her expected payoff is larger than 0 , which is the payoff when he or she does not run in the election. In short, $w-\alpha\left(0-z_{i}\right)^{2}-c>0$, and, hence, $z_{i} \in[-\theta, \theta] . \mu_{i}$ and $\sigma_{i}$ for $z_{i} \in[-\theta, \theta]$ are 0 and $\frac{1}{3} \theta^{2}$, respectively. On the other hand, the expected payoff of the median voter at 0 if the incumbent is elected is

$$
-\left(0-z_{i}\right)^{2}-0 \text {. }
$$

Then, in the second election, for the incumbent to win,

$$
-\frac{\theta^{2}}{3}<-z_{i}^{2}
$$

In short, if $z_{i} \in\left[-\frac{\sqrt{3}}{3} \theta, \frac{\sqrt{3}}{3} \theta\right]$, the challenger loses, and the incumbent wins.

Otherwise, since the challenger is going to win, the incumbent does not run for reelection. Next, we go back to the first period. Note that, in the first election, candidates who join the party (and win) lie in

$$
z_{i} \in[-\theta, \theta] .
$$

This is the same result as in Snyder and Ting [1]. A candidate's nomination and platform selection are independent of introducing the second election. To sum up, in the first election, candidates $z_{i} \in[-\theta, \theta]$ join the party. In the second election, candidates $z_{i} \in\left[-\frac{\sqrt{3}}{3} \theta, \frac{\sqrt{3}}{3} \theta\right]$ run for reelection. In other words, only incumbents in the narrower range can run for reelection and win office.

${ }^{1}$ This is the equilibrium when $\theta<\sqrt{3} / 2$ in Snyder and Ting [1]. Related studies about this platform selection are Bernhardt and Ingberman [7], Calvert [8], Palfrey [9], and Snyder [10]. 
Based on these politicians' behavior, there are three types of candidates:

Loser: If $z_{i} \in[-1,-\theta]$ or $z_{i} \in[\theta, 1]$, the politician does not join a party. We refer to such a politician as a "loser".

One-Time Winner: If $z_{i} \in\left[-\theta,-\frac{\sqrt{3}}{3} \theta\right]$ or $z_{i} \in\left[\frac{\sqrt{3}}{3} \theta, \theta\right]$, the politician joins a party but does not get reelected. We refer to such a politician as a "one-time winner".

Two-Time Winner: If $z_{i} \in\left[-\frac{\sqrt{3}}{3} \theta, \frac{\sqrt{3}}{3} \theta\right]$, the politician joins a party and gets reelected. We refer to such a politician as a "two-time winner".

We find that a "loser" does not join a party. Therefore, we can say that joining a party works to signal a politician's type to some extent. We also find that one-time winners are found to be unfavorable to the voters after one term in office, even though they were elected in the first election.

Because each party selects one candidate, the first election has three possibilities $^{2}$ :

\section{- One-Time Winner vs. One-Time Winner}

Both of these politicians join parties, and one of them gets elected with $50 \%$ probability in the first election but does not get reelected.

\section{- Two-Time Winner vs. One-Time Winner}

Both of these politicians join parties, one of them gets elected with 50\% probability in the first election, and only the two-time winner can get reelected.

\section{- Two-Time Winner vs. Two-Time Winner}

Both of these politicians join parties, and one of them gets elected with 50\% probability in the first election and gets reelected.

As is shown above, joining a party works as a signal to some extent. However, there is still a problem with voting for the most favored candidate. If promising candidates (two-time winners) compete against non-promising candidates (onetime winners), promising candidates have only a 50\% chance of winning. This fact implies that political parties are not sufficient signals.

The main result is as follows. Incumbents in a narrower range can run for reelection and win office. However, joining a political party does not differentiate between ex-post good politicians (who can get reelected) and ex-post bad politicians (who cannot get reelected). We can say that political parties do not work sufficiently for the voters to choose their favored candidates.

\section{Introducing Reelection and Advertisements to the Basic Model}

\subsection{Timing of the Model}

As seen in the previous section, political parties are not sufficient signals. Next, by introducing political advertisements to the model discussed above, we would like to answer the question of what the role of political advertisements is. The ${ }^{2}$ For simplicity, we omit losers from the following list. 
main result is that political advertisements work as a complementary signal to political parties. Promising (ex-post good) candidates design political advertisements to differentiate themselves from other candidates even if advertisements are simply a waste of money.

The timing of the model is as follows. Stage 3 is added to the model described above; in other words, before the first vote, candidates can design political advertisements.

1) First Period Starts. Party Platform Selection.

2) Candidate Nomination and Selection.

3) Candidates' Political Advertisements

4) $1^{\text {st }}$ Vote. $1^{\text {st }}$ Term of Office.

5) Second Period Starts. Candidate Nomination and Selection.

6) $2^{\text {nd }}$ Vote. $2^{\text {nd }}$ Term of Office.

The important point to note is that advertisements neither affect the payoffs of the voters nor convey any information except their quantity; therefore, political advertisements are simply a waste of money in the same sense as in Milgrom and Roberts [6]. However, the important point is that the amount of money spent on political advertisement becomes known to the public. This setting is natural because in reality political advertisements often call candidates' names repeatedly, convey any information about candidates' policy planning, and voters only know which candidate use more advertisements.

Promising candidates who can win office twice want to design political advertisements to send more signals to the public before the first election. This property is because, as seen in the previous section, in the first election, simply joining a party does not differentiate a two-time winner from a one-time winner, although it does differentiate a winner from a loser. To be more precise, in equilibrium, each candidate type can win the first election with $50 \%$ probability. However, if the candidate were known to voters as a two-time winner, he or she would win the election with $100 \%$ probability. Therefore, he or she has the incentive to reveal his or her hidden type by designing advertisements.

\subsection{The Equilibrium}

Whether or not candidates use political advertisements depends on the opponent's type and policy. We use the same definitions of a "loser", a "one-time winner", and a "two-time winner" as before; a candidate is called a loser if $z \in[-1,-\theta]$ or $z \in[\theta, 1]$, a candidate is called a one-time winner if $z \in\left[-\theta,-\frac{\sqrt{3}}{3} \theta\right]$ or $z \in\left[\frac{\sqrt{3}}{3} \theta, \theta\right]$, and a candidate is called a two-time winner if $z \in\left[-\frac{\sqrt{3}}{3} \theta, \frac{\sqrt{3}}{3} \theta\right]$. As before, a one-time winner cannot win reelection and a two-time winner can win reelection.

Because each party selects one candidate, the first vote has three possibilities:

- One-Time Winner vs. One-Time Winner 
- if $\theta^{2}<2\left|z_{j}\right|^{2}-\left|z_{i}\right|^{2}$, the promising candidate uses both a party and advertisements.

- if $\theta^{2}>2\left|z_{j}\right|^{2}-\left|z_{i}\right|^{2}$, the promising candidate uses only a party.

- Two-Time Winner vs. One-Time Winner

- the promising candidate uses both a party and advertisements.

- Two-Time Winner vs. Two-Time Winner

- if $\theta^{2}<\left|z_{j}\right|^{2}-\frac{1}{2}\left|z_{i}\right|^{2}$, the promising candidate uses both a party and advertisements.

- if $\theta^{2}>\left|z_{j}\right|^{2}-\frac{1}{2}\left|z_{i}\right|^{2}$, the promising candidate uses only a party.

In the Appendix, we derive each equilibrium. Whether candidates use advertisements or not depends on their relative positions. It should be noted that in the "two-time winner vs. one-time winner" case, only two-time winners use both a party and advertisements. In short, with advertisements, the voters can distinguish a two-time winner from a one-time winner, whereas, in the previous section without advertisements, they cannot distinguish the two types. Then, by voting for the candidates who use advertisements, the voters can select a favorable candidate in the election. The implication is also similar in the other situations. If the candidates are located far enough apart, the promising candidate joins a party and also uses advertisements. With advertisements, voters can distinguish promising and favorable candidates in the election. From these results, we can conclude that political advertisements work as a complement to political parties.

\section{Why Are Advertisements Complementary?}

In the previous section, we have found that both political parties and political advertisements work as signals to voters. In some cases candidates only use parties, and in other cases candidates use parties and advertisements. It seems that candidates' first priority is joining parties. In this section, we would like to explain why the priority is political parties, and why advertisements serve as complement to parties.

Basically, political parties work as more efficient signals than advertisements. This is because belonging to parties costs candidates heterogeneously, whereas creating advertisements costs candidates homogeneously. First, consider political parties. Candidates who are located further from the parties' ideal policies pay a larger cost to join the parties than do candidates who are located nearer to the parties' ideal policies. This fact is represented in (1). Next, consider political advertisements. When candidates use political advertisements, all of them pay the same cost to create the same amount of advertisements. In short, joining a party is a better signal for a promising candidate than advertisements are because joining a party costs less.

Therefore, in all cases, promising candidates who are located nearer to the parties' ideal policies first join political parties. However, belonging to parties is 
sometimes not enough for candidates to differentiate themselves from the other candidates. In this case, they need an additional signal, political advertisements, even though advertisements are less efficient for promising candidates. When is the first signal, joining a party, not enough? The answer is mainly when the gain from winning an election is very different among the candidates (e.g., in the case of a two-time winner vs. a one-time winner). Then, candidates have stronger incentives to differentiate themselves from the other candidates. They use less efficient political advertisements in addition to joining political parties.

Political advertisements work as complementary signals to political parties. With the two signals, promising candidates can allow voters to distinguish them from the other candidates. Voters can choose adequate candidates even in the first election.

\section{Summary}

Let us summarize the main points of this paper. Investigating a multi-period version of Snyder and Ting [1], we study the signaling aspects of political parties and political advertisements. Political advertisements work as a complementary signal to political parties; political parties are basically more efficient signals than political advertisements are. However, candidates who have strong incentives to win and require more signals use advertisements in addition to joining parties.

We can conclude that both political parties and advertisements help voters to adequately choose ex-post good politicians in elections. Although political advertisements can be regarded as a social cost in a sense that they do not directly yield any utility or gain, they work as a signaling tool that conveys correct information about politicians' types.

There are limitations on this study. First, we analyze two-period version of Snyder and Ting [1]. It is possible for us to add more periods to the model. The results would change to some extent. Second, in our definition of political advertisements, they do not convey any information about the hidden types of the candidates. However, in reality, some advertisements are informative. We have to evaluate this kind of advertisements on a case-by-case basis.

\section{Acknowledgements}

I would like to thank Professor Masayuki Otaki for his helpful comments. I am also grateful to seminar participants at the University of Tokyo for fruitful discussions.

\section{References}

[1] Snyder Jr., J.M. and Ting, M.M. (2002) An Informational Rationale for Political Parties. American Journal of Political Science, 46, 90-110. https://doi.org/10.2307/3088416

[2] Spence, M. (1974) Market Signalling. Harvard University Press, Cambridge.

[3] Alesina, A. and Spear, S.E. (1988) An Overlapping Generations Model of Electoral Competition. Journal of Public Economics, 37, 359-379. 
https://doi.org/10.1016/0047-2727(88)90047-3

[4] Harrington Jr., J.E. (1992) The Role of Party Reputation in the Formation of Policy. Journal of Public Economics, 49, 107-121. https://doi.org/10.1016/0047-2727(92)90066-O

[5] Biglaiser, G. and Mezzetti, C. (1997) Politicians' Decision Making with Re-Election Concerns. Journal of Public Economics, 66, 425-447. https://doi.org/10.1016/S0047-2727(97)00032-7

[6] Milgrom, P. and Roberts, J. (1986) Price and Advertising Signals of Product Quality. Journal of Political Economy, 94, 796-821. https://doi.org/10.1086/261408

[7] Bernhardt, D.M. and Ingberman, D.E. (1985) Candidate Reputations and the 'Incumbency' Effect'. Journal of Public Economics, 27, 47-67. https://doi.org/10.1016/0047-2727(85)90028-3

[8] Calvert, R. (1985) Robustness of the Multidimensional Voting Model: Candidate Motivations, Uncertainty, and Convergence. American Journal of Political Science, 29, 69-95. https://doi.org/10.2307/2111212

[9] Palfrey, T.R. (1984) Spatial Equilibrium with Entry. Review of Economic Studies, 51, 139-156. https://doi.org/10.2307/2297710

[10] Snyder Jr., J.M. (1994) Safe Seats, Marginal Seats, and Party Platforms: The Logic of Party Platform Differentiation. Economics and Politics, 6, 201-213.

https://doi.org/10.1111/j.1468-0343.1994.tb00097.x 


\section{Appendix}

In this appendix, we show the equilibrium of Section 4 in more detail.

\section{1) Equilibrium: One-Time Winner vs. One-Time Winner}

The first case is that candidates $i$ and $j$ are both one-time winners. We assume that $i$ is closer to the median voter than $j$ is. As a result, at the equilibrium, if $\theta^{2}<2\left|z_{j}\right|^{2}-\left|z_{i}\right|^{2}$,

- A "loser" does not join a party, does not use advertisements, and cannot win at all.

- "One-time winner" $j$ joins a party, does not use advertisements, and cannot win the first election.

- "One-time winner" $i$ joins a party, uses advertisements $a d_{i}=w-c-\alpha z_{j}^{2}$, wins the first election with $100 \%$ probability, but does not get reelected. If $\theta^{2}>2\left|z_{j}\right|^{2}-\left|z_{i}\right|^{2}$,

- A "loser" does not join a party, does not use advertisements, and cannot win at all.

- "One-time winners" $i$ and $j$ join parties, do not use advertisements, can win the first election with $50 \%$ probability, but do not get reelected.

Note that the beliefs of voters are formed rationally ${ }^{3}$, as in Snyder and Ting [1].

Let us verify that the above is the equilibrium. Suppose that candidate $j \mathrm{~s}$ strategy is to join a party and use no advertisements. In the following, we check whether or not candidate $i s$ best response is the above strategy. Note that there are three options for the candidates to choose: (A) only join a party, (B) only use advertisements, and $(C)$ both join a party and use advertisements.

For candidate $i$, option (A) provides a gain of

$$
\frac{1}{2}\left[\left(w-c-\alpha z_{i}^{2}\right)\right] \text {. }
$$

This result is because both $i$ and $j$ are seen as part of the same group, and candidate $i$ s probability of winning is $\frac{1}{2}$.

Next, in option (B), candidate $i$ only uses advertisements. The amount of advertisements that candidate $i$ purchases is

$$
a d_{i}=w-c .
$$

Candidate $i$ has to pay $w-c$ for advertisements because he or she has to differentiate himself or herself from candidate $j$ and non-party-affiliated candidates. If either candidate wins, he or she would gain $w-c$ in the first term of office. Therefore, candidate $i$ pays the larger amount $w-c$ to create differentiation from the other candidates and win the election. Then, for candidate $i$, option (B) provides a gain of

${ }^{3}$ To be precise, the beliefs are as follows. 1) If a candidate does not join a party and $a d<w-c$, then he or she is $z_{j}$, or a loser. 2) If a candidate does not join a party and $a d \geq w-c$, then he or she is $\left.Z_{i} .3\right)$ If a candidate joins a party and $a d<w-c-\alpha z_{j}^{2}$, then he or she is $\left.z_{j} .4\right)$ If a candidate joins a party and $a d \geq w-c-\alpha z_{i}^{2}$, then he or she is $Z_{i}$. 


$$
\begin{aligned}
w-c-a d_{i} & =(w-c)-(w-c) \\
& =0 .
\end{aligned}
$$

In option (C), candidate $i$ joins a party and additionally uses advertisements. Although joining a party serves to differentiate this candidate from unaffiliated candidates, advertisements work to differentiate this candidate from the other party-affiliated candidate. Therefore, the amount of advertisements is

$$
a d_{i}=w-c-\alpha z_{j}^{2},
$$

which is equal to the gain of candidate $j$, since candidate $j$ cannot pay that amount of money even if he or she can win the election. Then, the voters can elect the better candidate even in the first election. For candidate $i$, option (C) provides a gain of

$$
\begin{array}{r}
\left(w-c-\alpha z_{i}^{2}\right)-\left(w-c-\alpha z_{j}^{2}\right) \\
=\alpha z_{j}^{2}-\alpha z_{i}^{2} .
\end{array}
$$

Comparing options (A), (B), and (C), we can say that the candidates' best responses depend on their relative positions. If $\theta^{2}<2\left|z_{j}\right|^{2}-\left|z_{i}\right|^{2}$, candidate $i$ chooses option (C) and gets elected. If $\theta^{2}>2\left|z_{j}\right|^{2}-\left|z_{i}\right|^{2}$, candidate $i$ chooses option (A) and gets elected with probability $\frac{1}{2}$. On the other hand, it is clear that in both cases, candidate $j \mathrm{~s}$ best response is to also join a party and create no advertisements. Therefore, we can conclude that these strategies are candidate is and $j$ s strategies in the equilibrium.

\section{2) Equilibrium: Two-Time Winner vs. One-Time Winner}

The next case is that one candidate, $i$, is a two-time winner and the other candidate, $j$, is a one-time winner. We assume that $i$ is closer to the median voter than $j$ is. At the equilibrium,

- A "loser" does not join a party, does not use advertisements, and cannot win at all.

- "One-time winner" $j$ joins a party, does not use advertisements, and cannot win the first election.

- "Two-time winner" $i$ joins a party, creates advertisements $a d_{i}=w-c-\alpha z_{j}^{2}$, wins the first election with $100 \%$ probability, and gets reelected.

Note that the beliefs of voters are formed rationally ${ }^{4}$, as in Snyder and Ting [1].

Let us verify that the above is the equilibrium. Suppose that candidate $j \mathrm{~s}$ strategy is to join a party and use no advertisements. In the following, we check whether or not candidate is best response is the above strategy. Note that there are three options for the candidates to choose: (A) only join a party, (B) only use advertisements, and $(\mathrm{C})$ both join a party and use advertisements.

${ }^{4}$ To be precise, the beliefs are as follows. 1) If a candidate does not join a party and $a d<w-c$, then he or she is $z_{j}$, or a loser. 2) If a candidate does not join a party and $a d \geq w-c$, then he or she is $\left.Z_{i} .3\right)$ If a candidate joins a party and $a d<w-c-\alpha z_{j}^{2}$, then he or she is $\left.z_{j} .4\right)$ If a candidate joins a party and $a d \geq w-c-\alpha z_{i}^{2}$, then he or she is $Z_{i}$. 
For candidate $i$, option (A) provides a gain of

$$
\frac{1}{2}\left[\left(w-c-\alpha z_{i}^{2}\right)+(w-c)\right] .
$$

This result is because both $i$ and $j$ are seen as part of the same group and candidate $i$ s probability of winning is $\frac{1}{2}$.

Next, in option (B), candidate $i$ only uses advertisements. The amount of advertisements that candidate $i$ purchases is

$$
a d_{i}=w-c .
$$

Candidate $i$ has to pay $w-c$ for advertisements because he or she has to differentiate himself or herself from candidate $j$ and non-party-affiliated candidates. If either candidate wins, then he or she gains $w-c$ in the first term of office. Therefore, candidate $i$ pays the larger amount $w-c$ to create differentiation from the other candidates and win the election. Then, for candidate $i$, option (B) provides a gain of

$$
\begin{aligned}
2(w-c)-a d_{i} & =2(w-c)-(w-c) \\
& =w-c .
\end{aligned}
$$

In option (C), candidate $i$ joins a party and uses advertisements. Whereas joining a party works to differentiate this candidate from the unaffiliated candidate, advertisements work to differentiate this candidate from the other party-affiliated candidate. Therefore, the amount of advertisements is

$$
a d_{i}=w-c-\alpha z_{j}^{2},
$$

which is equal to the gain of the other affiliated candidate, since $j$ cannot pay that amount of money even if he or she can win the election. The voters can then distinguish between the better and worse candidate even in the first election by observing whether the candidates have advertised or not. For candidate $i$, option (C) gives

$$
\begin{gathered}
\left(w-c-\alpha z_{i}^{2}\right)-\left(w-c-\alpha z_{j}^{2}\right)+(w-c) \\
=w-c+\alpha z_{j}^{2}-\alpha z_{i}^{2} .
\end{gathered}
$$

Comparing options (A), (B), and (C), we can say that candidate $i$ s best strategy is option (C), joining a party and creating advertisements. As a result, candidate $i$ gets elected. On the other hand, it is clear that candidate $j$ s best response is to join a party and use no advertisements. Therefore, we can conclude that these strategies are candidate $i$ s and $j$ s strategies in the equilibrium.

\section{3) Equilibrium: Two-Time Winner vs. Two-Time Winner}

The last case is that candidates $i$ and $j$ are both two-time winners. We assume that $i$ is closer to the median voter than $j$ is. As a result, at the equilibrium, if $\theta^{2}<\left|z_{j}\right|^{2}-\frac{1}{2}\left|z_{i}\right|^{2}$,

- A "loser" does not join a party, does not use advertisements, and cannot win 
at all.

- “Two-time winner" $j$ joins a party, does not use advertisements, and cannot win the first election.

- “Two-time winner" $i$ joins a party, uses advertisements $a d_{i}=2(w-c)-\alpha z_{j}^{2}$, wins the first election with $100 \%$ probability, and gets reelected.

If $\theta^{2}>\left|z_{j}\right|^{2}-\frac{1}{2}\left|z_{i}\right|^{2}$,

- A "loser" does not join a party, does not use advertisements, and cannot win at all.

- “Two-time winners" $i$ and $j$ join parties, do not use advertisements, can win the first election with $50 \%$ probability, and can get reelected.

Note that the beliefs of voters are formed rationally ${ }^{5}$, as in Snyder and Ting $[1]$.

Let us verify that the above is the equilibrium. Suppose that candidate $j$ s strategy is to join a party and create no advertisements. In the following, we check whether or not candidate is best response is the above strategy. Note that there are three options for the candidates to choose: (A) only join a party, (B) only use advertisements, and $(C)$ both join a party and use advertisements.

For candidate $i$, option (A) provides a gain of

$$
\frac{1}{2}\left[\left(w-c-\alpha z_{i}^{2}\right)+(w-c)\right] .
$$

This result is because both $i$ and $j$ are seen as part of the same group, and the probability of winning is $\frac{1}{2}$.

Next, in option (B), candidate $i$ only uses advertisements. The amount of advertisements that candidate $i$ purchases is

$$
a d_{i}=2(w-c) \text {. }
$$

Candidate $i$ has to pay $w-c$ for advertisements because he or she has to differentiate himself or herself from candidate $j$ and non-party-affiliated candidates. If they win, candidate $j$ gains $2(w-c)$ and non-party-affiliated candidates gain $w-c$ in the first term of office. Therefore, candidate $i$ pays the larger amount $2(w-c)$ to create differentiation from the other candidates and win the election. Then, for candidate $i$, option (B) provides a gain of

$$
\begin{aligned}
2(w-c)-a d_{i} & =2(w-c)-2(w-c) \\
& =0 .
\end{aligned}
$$

In option (C), candidate $i$ joins a party and uses advertisements. Whereas joining a party works to differentiate this candidate from the unaffiliated candidate, advertisements work to differentiate this candidate from the other par-

${ }^{5}$ To be precise, the beliefs are as follows. 1) If a candidate does not join a party and $a d<2(w-c)$, then he or she is $z_{j}$, or a loser. 2) If a candidate does not join a party and $a d \geq 2(w-c)$, then he or she is $\left.z_{i} .3\right)$ If a candidate joins a party and $a d<2(w-c)-\alpha z_{j}^{2}$, then he or she is $\left.z_{j} .4\right)$ If a candidate joins a party and $a d \geq 2(w-c)-\alpha z_{i}^{2}$, then he or she is $Z_{i}$. 
ty-affiliated candidate. Therefore, the amount of advertisements is

$$
a d_{i}=\left(w-c-\alpha z_{j}^{2}\right)+(w-c),
$$

which is equal to the gain of the other affiliated candidate, since $j$ cannot pay that amount of money even if he or she can win the election. The voters can then distinguish between the better and worse candidate even in the first election by observing whether the candidates have advertised or not. For candidate $i$, option (C) gives

$$
\begin{array}{r}
\left\{\left(w-c-\alpha z_{i}^{2}\right)-\left[\left(w-c-\alpha z_{j}^{2}\right)+(w-c)\right]\right\}+w-c \\
=\alpha z_{j}^{2}-\alpha z_{i}^{2} .
\end{array}
$$

Comparing options (A), (B), and (C), we can say that candidates' best responses depend on their relative positions. If $\theta^{2}<\left|z_{j}\right|^{2}-\frac{1}{2}\left|z_{i}\right|^{2}$, candidate $i$ chooses option (C) and gets elected. If $\theta^{2}>\left|z_{j}\right|^{2}-\frac{1}{2}\left|z_{i}\right|^{2}$, candidate $i$ chooses option (A) and gets elected with probability $\frac{1}{2}$. On the other hand, it is clear that in both cases, candidate $j$ s best response is to join a party and create no advertisements. Therefore, we can conclude that these strategies are candidate is and $j$ s strategies in the equilibrium. 